Reprod. Nutr. Dévelop., 1985, 25 (4 B), 729-753.

\title{
Le fermenteur rumen
}

P. THIVEND (1), G. FONTY $\left({ }^{2}\right)\left({ }^{4}\right)$, J. P. JOUANY (1), Michelle DURAND $\left({ }^{3}\right)$, Ph. GOUET (2)

(1) Laboratoire de la Digestion, I.N.R.A., Theix 63122 Ceyrat.

(2) Laboratoire de Microbiologie, I.N.R.A., Theix 63122 Ceyrat.

(3) Station de Recherches de Nutrition, I.N.R.A., 78350 Jouy-en-Josas.

(4) Laboratoire de Biologie des Protistes, L.A. 138 C.N.R.S., Université de Clermont II, B.P. 45, 63170 Aubière.

Summary. The rumen fermenter.

The two main pregastric compartiments of ruminants (rumen and reticulum) can be compared to an anaerobic fermenter which allows them to use energetic and nitrogen substrates which are indigestible by monograstric animals. The aim of this bibliographic review is to describe the main features (characteristics) of this fermenter, focusing on the role of microbes (bacteria, protozoa and fungi), on the degradation of cell-wall carbohydrates (cellulose, hemicelluloses, pectic substances), on nitrogen digestion and finally on the utilisation of the major minerals and trace elements.

\section{Introduction}

Anatomie des réservoirs gastriques du ruminant

\section{Les constituants biotiques de l'écosystème}
A) Les bactéries
B) Les protozoaires
C) Les autres micro-organismes

Localisation des microorganismes dans le rumen
A) Les bactéries
B) Les protozoaires
C) Les champignons

\section{Quelques caractéristiques du fermenteur rumen}

1) La dégradation des glucides des parois végétales

2) L'utilisation de l'azote non protéique

3) Eléments minéraux et digestion microbienne

\section{Conclusions}




\section{Introduction}

Les microorganismes sont présents en nombre variable dans les réservoirs gastriques des mammifères. Chez les animaux qui ne possèdent qu'un seul estomac (monogastriques), leur nombre est généralement faible et leur développement est souvent lié à l'arrivée des aliments auxquels ils sont associés. Les fermentations qui en résultent sont habituellement de type lactique et n'ont, d'une façon générale, que peu d'impact sur l'intensité de la digestion. Une des principales causes du faible développement de ces fermentations est l'importance des sécrétions acides dans la région pylorique. Les microorganismes attachés à l'épithelium de l'estomac sont essentiellement des levures et des lactobacilles qui peuvent proliférer en milieu acide.

Dans les préestomacs ou dans l'estomac de la plupart des herbivores, les conditions sont complètement différentes. La complexité anatomique de ces réservoirs est associée à la présence d'une population dense et stable de microorganismes qui vivent en symbiose avec l'hôte et qui jouent un rôle capital dans la digestion et la nutrition de l'animal. La mise en place et le maintien de cette population microbienne sont dus au fait qu'il existe une séparation physique entre la zone de sécrétion acide (estomac) et le reste des préestomacs où la digestion microbienne peut avoir lieu en permanence.

Parmi les mammifères, les Ruminants sont, de loin, ceux chez qui la digestion microbienne prégastrique est la plus développée mais il existe un nombre important d'autres mammifères possédant également ces caractéristiques (tabl. 1).Les ruminants constituent un sous-ordre des Artiodactyles, extrêmement important par leur nombre et leur rôle économique. Leur apparition date de l'oligocène et coïncide avec le développement des angiospermes (fig. 1). Elle fut précédée par le développement des Périssodactyles (cheval, zèbre, tapir, rhinocéros) et par celui des porcs et des hippopotames. L'explication du développement des

TABLEAU 1

Famille de mammifères possédant une digestion microbienne gastrique ou prégastrique.

\begin{tabular}{|c|c|c|}
\hline Ordre & & Famille \\
\hline Marsupiaux & Macropodidée & (Kangourou) \\
\hline Primates & $\begin{array}{l}\text { Cercopithécidae, sous } \\
\text { famille des Colobinés }\end{array}$ & (Singes Colobes) \\
\hline Edentés & Bradipodidae & (Tapir) \\
\hline Artiodactyles & Hippopotamidae & (Hippopotame) \\
\hline & Camélidés & (Chameau) \\
\hline & Tragulidés & (Chevrotin) \\
\hline & Cervidés & (Cerf) \\
\hline & Girafidés & (Girafe, Okapi) \\
\hline & Antilocapridés & (Gazelle américaine) \\
\hline & Bovidés & (Bovins, Moutons, Chères, Gazelles) \\
\hline
\end{tabular}


Ruminants à cette période n'est pas claire. Elle tient certainement à la présence des processus de fermentation prégastrique qui auraient joué un rôle important dans la détoxication des composés des plantes existantes permettant aussi à ce type d'animal un choix plus large et une meilleure adaptation au milieu (Freeland et Janzen, 1974). On pense aussi plus communément que le développement des préestomacs aurait permis aux ruminants, en autorisant un stockage rapide des aliments ingérés, d'échapper aux prédateurs...

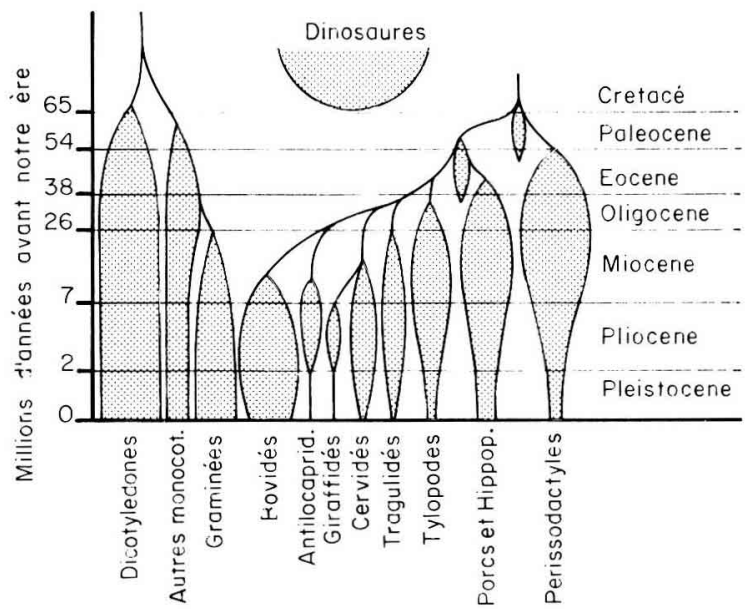

FIG. 1. - Schéma montrant l'apparition et le développement des ongulés et des angiospermes depuis la disparition des dinosaures.

Actuellement, les ruminants sont divisés en cinq familles comprenant 165 espèces différentes, la plupart d'entre elles vivant à l'état sauvage (tabl. 2). Parmi les espèces domestiques, ce sont les bovidés qui sont les plus nombreux (2 200 millions de têtes de bovins et d'ovins dans le monde sur une population totale d'herbivores domestiques d'environ 3000 millions) (Jarrige, 1980a). C'est dire leur

TABLEAU 2

Classification des ruminants.

\begin{tabular}{|c|c|c|c|c|}
\hline & Famille & $\begin{array}{l}\text { Nombre de } \\
\text { genres }\end{array}$ & $\begin{array}{c}\text { Nombre } \\
\text { d'especes }\end{array}$ & Exemple \\
\hline Ruminants & $\begin{array}{l}\text { Tragulidés } \\
\text { Girafidés } \\
\text { Antilocapridés } \\
\text { Cervidés } \\
\text { Bovidés }\end{array}$ & $\begin{array}{r}2 \\
2 \\
1 \\
17 \\
54\end{array}$ & $\begin{array}{r}4 \\
2 \\
1 \\
38 \\
120\end{array}$ & $\begin{array}{l}\text { Chevrotain } \\
\text { Girafe, Okapi } \\
\text { Antilope américaine } \\
\text { Cerf, Caribou, Elan } \\
\text { Antilope, Bison, Buffle, } \\
\text { Bovin, Gazelle, Chèvre, } \\
\text { Mouton }\end{array}$ \\
\hline Tylopodes & Camélidés & 2 & 4 & Chameau, Alpaga, Lama \\
\hline
\end{tabular}


importance et l'intérêt que l'on peut y porter quand on sait que les ruminants fournissent 70 à $75 \%$ des produits d'origine animale consommables dans les monde (Jarrige, 1980a), que leurs potentialités peuvent être encore largement exploitées (la digestibilité moyenne des aliments est de l'ordre de $60 \%$ alors qu'elle est voisine de 85 à $90 \%$ chez les monogastriques), qu'il existe encore de très nombreuses espèces non utilisées (en particulier dans les zones tropicales et subtropicales) et qu'enfin, les ruminants sont les seuls mammifères domestiques (avec les équidés) dont l'alimentation n'entre pas en concurrence avec celle de I'homme. Pour améliorer les performances de ces animaux et l'efficacité de la transformation des aliments, il est donc nécessaire de bien connaître les mécanismes de la digestion microbienne (qui explique à elle seule 80 à $100 \%$ de la dégradation de la matière organique ingérée), afin de pouvoir optimiser le rendement des fermentations qui se développent dans les réservoirs pré-gastriques.

\section{Anatomie des réservoirs pré-gastriques : rappels}

L'appareil digestif des ruminants est composé de 3 compartiments placés avant la caillette qui est le véritable estomac. Ce sont successivement le rumen (ou panse) le réseau (ou réticulum) et le feuillet (ou omasum). Leur anatomie et leur physiologie commencent à être bien connues et ont été largement décrites. Nous nous contenterons d'en rappeler les principales caractéristiques, en renvoyant le lecteur aux revues de synthèse ou aux articles spécialisés publiés dans de nombreux ouvrages au cours de ces dernières décennies (Jacquot, Le Bars et Simonnet, 1958 ; Hungate, 1966 ; Church, 1975 ; Jarrige, 1978 ; Van Soest, 1982 ; Dougherty, 1985 ; Phillipson, 1970 ; Mc Donald et Warner, 1975 ; Ruckebusch et Thivend, 1980).

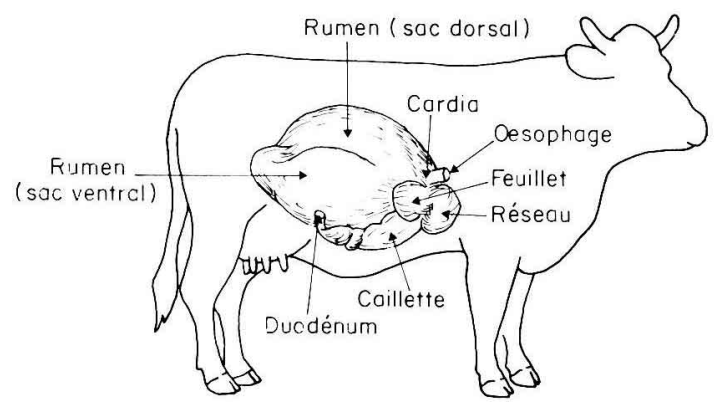

FIG. 2. - Anatomie des réservoirs gastriques du ruminant.

Le rumen est de loin le plus volumineux des réservoirs pré-gastriques. Selon les types de ruminant et de ration, il renferme de 70 à $75 \%$ du contenu total du tube digestif et représente de 50 à $60 \%$ de son volume. II s'ouvre très largement vers l'avant sur le réseau qui peut être considéré comme un diverticule du rumen. Quand on parle de la digestion dans le rumen, on inclut toujours le réseau. La surface intérieure du rumen, à l'exception des piliers charnus qui le divisent en plusieurs sacs, est constituée par un épithélium corné, hérissé de papilles de formes 
et de dimensions variables, nombreuses, serrées les unes contre les autres, et qui jouent un rôle majeur dans l'absorption des produits du métabolisme des microorganismes du rumen : acides gras volatils (A. G. V.), ammoniac.

Le réseau qui doit son nom à sa muqueuse réticulée et parsemée également de papilles absorbantes, joue un rôle central dans la circulation des particules. C'est du réseau que partent, à une fréquence de l'ordre d'une minute, les contractions qui assurent la motricité de l'ensemble des réservoirs gastriques (Ruckebusch et Kay, 1971). Les particules qui franchissent l'orifice réticulo-omasal doivent avoir une taille moyenne inférieure ou égale à $1 \mathrm{~mm}$. Les aliments solides sont donc " séquestrés " dans le rumen tant qu'ils n'ont pas acquis la taille minimale. Celle-ci est atteinte en un temps plus ou moins long (de quelques heures à plusieurs jours) sous l'action combinée des enzymes de la population microbienne et de la mastication lors de l'ingestion et de la rumination (ou mastication mérycique).

Le feuillet est un organe sphérique (bovin) ou ovoïde (mouton) à l'intérieur duquel on trouve de très nombreuses lames recouvertes d'un épithélium kératinisé, qui possède également des papilles. La cavité du feuillet est limitée à un canal qui communique en amont avec le réseau par un sphincter ( sphincter réticulo-omasal), en aval avec la caillette par un orifice beaucoup plus large et dilatable.

La caillette est le seul réservoir sécrétoire de l'estomac des ruminants. Sa cavité est tapissée par une muqueuse glandulaire, analogue à celle des monogastriques, toujours recouverte d'une couche de mucus. Les fonctions digestives de la caillette du ruminant sont analogues à celles de l'estomac des mammifères monogastriques.

Le contenu du rumen est un milieu relativement constant qui évoque à certains égards celui d'un réacteur en continu de micro-organismes anaérobies. II se caractérise par:

- une concentration élevée en eau : 85 à $90 \%$;

- une température constante de 39 à $40^{\circ} \mathrm{C}$;

- un potentiel d'oxydo-réduction variant de -250 à $-400 \mathrm{mv}$ (milieu fortement anaérobie) ;

- un pH généralement compris entre 6 et 7 qui est tamponné par l'apport régulier de grandes quantités de bicarbonate et de phosphate contenus dans la salive ; - une pression osmotique constante proche de celle du sang ;

- un apport régulier de nutriments et d'eau fournis à la fois par l'ingestion des aliments et par la rumination ;

- une élimination continue des produits du métabolisme, soit par absorption à travers la paroi du rumen (acides gras volatils, ammoniac), soit par passage dans la partie postérieure du tube digestif (résidus alimentaires, cellules microbiennes), soit par éructation (méthane, gaz carbonique) ;

- une relative constance de l'atmosphère gazeuse située au niveau du sac dorsal $\left.1 \mathrm{CO}_{2}: 60-70 \% ; \mathrm{CH}_{4}: 30-40 \%\right)$;

- un brassage permanent assuré par les contractions périodiques de la paroi et par la rumination.

Le rumen est donc un milieu particulièrement bien adapté au développement 
d'une population microbienne anaérobie dont les principaux constituants sont les bactéries et les protozoaires.

\section{Les constituants biotiques de l'écosystème}

\section{A) Les bactéries}

La population bactérienne du rumen est comprise entre $8 \times 10^{9}$ et $4 \times 10^{10}$ cellules $\mathrm{ml}^{-1}$ de contenu. Elle constitue environ $50 \%$ de la biomasse microbienne et représente la catégorie de micro-organismes la plus complexe et la plus importante. Elle est composée essentiellement de bactéries anaérobies strictes non sporulées et elle est caractérisée par sa très grande diversité. En 1959, Bryant décrivait 39 genres et 63 espèces et actuellement plus de 200 espèces bactériennes ont été isolées du rumen. Une trentaine d'entre elles seulement peut être considérée comme des bactéries authentiques du rumen, les autres, apportées par la nourriture, n'étant présentes que d'une manière transitoire (Russel et Hespell, 1981).

Les bactéries du rumen sont généralement classées (Hungate, 1966) selon les substrats qu'elles sont capables de fermenter ou de dégrader : bactéries cellulolytiques, pectinolytiques, amylolytiques, uréolytiques, etc... Les fonctions de plusieurs espèces se recouvrent largement, ce qui contribue à la stabilité de l'écosystème (Hespell, 1981). Ainsi, la disparition d'une espèce ne provoquera pas d'effet négatif important au niveau de l'ensemble des fermentations et l'animal n'en souffrira pas.

Les fonctions d'une espèce donnée peuvent être limitées ou au contraire très larges. Ainsi, Butyrivibrio fibrisolvens, Bacteroides ruminicola, Selenomonas ruminantium peuvent utiliser de nombreuses sources d'énergie alors que les bactéries cellulolytiques par exemple, n'utilisent que la cellulose et ses produits d'hydrolyse. De même, Bacteroides amylophilus ne fermente que l'amidon, les dextrines et le maltose (Hungate, 1966 ; Bryant, 1977).

$D^{\prime}$ autres espèces sont encore plus spécialisées et occupent des niches écologiques très étroites : Anaerovibrio lipolytica n'hydrolyse que les lipides et ne fermente que le glycérol ; les Veillonella utilisent principalement le lactate (Hungate, 1966), Vibrio succinogenes ne tire son énergie que de la réduction du fumarate en succinate et Methanobacterium ruminantium, de la réduction du gaz carbonique en méthane (Wolin, 1975). De nombreuses espèces sont protéolytiques, plusieurs utilisent ou dégradent les acides aminés ou les peptides, mais de rares espèces telle que Megasphaera elsdenii peuvent croître à partir des acides aminés en l'absence de glucides comme source d'énergie (Bryant, 1977).

Quelques espèces bactériennes comme les Oscillospira, les "Quinn's oval 》, les « Eadie's oval ", fréquemment observées ou dénombrées par examen microscopique (Eadie, 1962), n'ont été que peu ou pas étudiées en culture pure. Leur fonction et leur métabolisme sont donc encore mal connus.

\section{B) Les protozoaires}

Les protozoaires du rumen sont essentiellement des ciliés mais on observe également la présence de flagellés, en nombre plus réduit. 
a) Les ciliés. - Ils appartiennent principalement à deux groupes, les Holotriches et les Entodiniomorphes. Parmi les holotriches, les genres /sotricha et Dasytricha (famille des /sotrichidae) sont les plus abondants; parmi les Entodiniomorphes, ce sont les genres Entodinium, Diplodinium, Epidinium, Ophryoscolex, Polyplastron et Eudiplodinium qui sont les plus fréquents (Clarke, 1977 ; Coleman, 1980 ; Grain, 1967 ; Hungate, 1966 ; Fonty et al., 1984). Leur nombre n'excède généralement pas 2 à $5 \times 10^{6}$ organismes $\mathrm{ml}^{-1}$ de contenu de rumen (Hungate, 1966). Cependant, dans certaines conditions d'alimentation, ils représentent au moins $50 \%$ de la biomasse microbienne du rumen. Du fait des difficultés à les cultiver in vitro, leur rôle et leur métabolisme sont moins connus que ceux des bactéries. Les protozaires ciliés sont capables de transformer un grand nombre de constituants alimentaires et bactériens en métabolites et en composés cellulaires qui seront ensuite utilisés par l'animal hôte. L'importance de ces activités est cependant encore très controversée puisqu'en l'absence de protozoaires dans le rumen, une fermentation bactérienne efficace continue.

Les Holotriches utilisent les glucides solubles, mais l'éventail des sucres métabolisés diffèrent dans les deux genres. /sotricha ne fermente pas le maltose mais peut utiliser les grains d'amidon tandis que Dasytricha fermente le maltose mais pas certains amidons (Clarke, 1977). La dégradation de la cellulose et des hémicelluloses n'a été démontrée dans aucun des deux genres. Cependant, ces ciliés possèdẹt une pectinestérase et une polygalacturonase (Clarke, 1977).

Les Entodiniomorphes ingèrent des particules végétales ou des grains d'amidon, à l'exception des espèces Entodinium de très petite taille. Des $\alpha$-amylases actives ont été mises en évidence dans plusieurs genres (Clarke, 1977 ; Coleman, 1980). La digestion de la cellulose par les Entodiniomorphes a été montrée pour la première fois in vitro par Hungate (1942), mais elle est restée longtemps controversée. Il est maintenant accepté que quelques genres au moins aient une activité cellulolytique (Bonhomme, 1973 ; Bonhomme-Florentin, 1975 ; Jouany, 1978 ; Coleman, 1980 ; Demeyer, 1981 ; Williams, 1982 ; Bonhomme et al., 1983). Plusieurs genres dégradent les hémicelluloses et les pectines (Clarke, 1977 ; Coleman, 1980 ; Williams, 1982). Par ailleurs, alors que l'on pensait à l'origine qu'ils étaient incapables d'utiliser les sucres, il est maintenant reconnu qu'Entodinium, Epidinium et Polyplastron peuvent métaboliser certains d'entre eux (Clarke, 1977 ; Jouany, 1978 ; Coleman, 1980).

Les ciliés sont également protéolytiques (Abou Akkada et Howard, 1962). Une population abondante de protozoaires est souvent associée à une concentration élevée en ammoniaque dans le rumen (Jouany, 1978). Ils utilisent les acides aminés (Coleman, 1980) mais leurs besoins azotés sont en grande partie couverts par l'ingestion des bactéries (Coleman, 1975).

b) Les flagellés. - Ils n'ont fait l'objet que d'un nombre très limité d'études et leur rôle dans l'écosystème n'est pas connu. Cinq espèces seulement ont été décrites: Monocercomonas ruminantium, Monocercomonö̈des caprae, Chilomastix caprae, Tetratrichomonas buttreyi et Pentatrichomonas homimis. Trois genres: Callimastix, Sphaeromonas et Piromonas initialement identifiés comme des protozoaires flagellés, sont en réalité des zoospores de champignons phycomycètes (Orpin, 1977). Les flagellés sont particulièrement abondants dans le 
rumen du jeune ruminant pendant la période précédant l'apparition des ciliés (Eadie, 1962). Chez l'adulte, du fait de leur faible nombre $\left(<10^{5} / \mathrm{ml}\right.$ (Eadie, 1962) et de leur taille réduite, leur rôle dans le rumen est insignifiant par rapport à celui des ciliés et des bactéries (Clarke, 1977).

\section{C) Autres micro-organismes}

a) Les champignons. - Plusieurs espèces de levures (Lund, 1974) et de champignons (Bauchop 1979, 1981 ; Orpin, 1984 ; Joblin, 1981) ont été isolées du rumen mais leur fonction et leur rôle dans la digestion microbienne n'ont été que peu étudiés. La plupart de ces micro-organismes apportés par l'aliment seraient simplement en transit dans le rumen. Certains Phycomycètes anaérobies stricts joueraient un rôle non négligeable dans la dégradation des polyholosides pariétaux (Bauchop, 1981 ; Orpin, 1984).

b) Les mycoplasmes. - Deux espèces de mycoplasmes anaérobies stricts ont été isolées du rumen : Anaeroplasma blastoclasticum et Anaeroplasma abactoclasticum (Robinson et al., 1975). Leur nombre varie entre $10^{5}$ et $10^{7}$ unités par $\mathrm{ml}$ de contenu de rumen. Leur rôle n'est pas connu.

c) Les bactériophages. - Une grande variété de bactériophages a été observée dans le rumen. Ces bactériophages lysent Streptococcus bovis (Iverson et Millis, 1977), Bifidobactérium thermophilum (Matteuzi et Sozzi, 1971) et les Eadie's oval (Orpin et Munn, 1974). Ritchie et al. (1970) distinguent jusqu'à 125 entités " phage-like " différentes dans le rumen de moutons ou de bovins mais les cellules hôtes n'ont pas été clairement identifiées. Les bactériophages tempérés et virulents peuvent jouer un rôle important dans l'écologie du rumen. A la suite d'une infection par un phage virulent, une espèce bactérienne peut devenir sousdominante. Son action pourra cependant être compensée par la prolifération d'une autre espèce non sensible, capable d'occuper la même niche écologique. En revanche, l'induction non spécifique de phages tempérés, par exemple par un facteur présent dans l'alimentation, peut entraîner la disparition de plusieurs espèces et ainsi avoir un effet négatif sur le bilan des fermentations et sur l'animal.

\section{Localisation des micro-organismes dans le rumen}

\section{A) Les bactéries}

Dans le rumen, les bactéries occupent trois biotopes distincts (Cheng et Costerton, 1980). Elles peuvent être libres dans le liquide de rumen, ou attachées soit à la paroi interne du rumen, soit aux particules alimentaires. Enfin, certaines espèces bactériennes vivent également liées à la surface des protozoaires (Imai et Ogimoto, 1978).

Bactéries libres. - Les bactéries libres dans le jus de rumen sont entourées par une structure fibreuse, polyholosidique (glycocalyx) (Cheng et Costerton, 


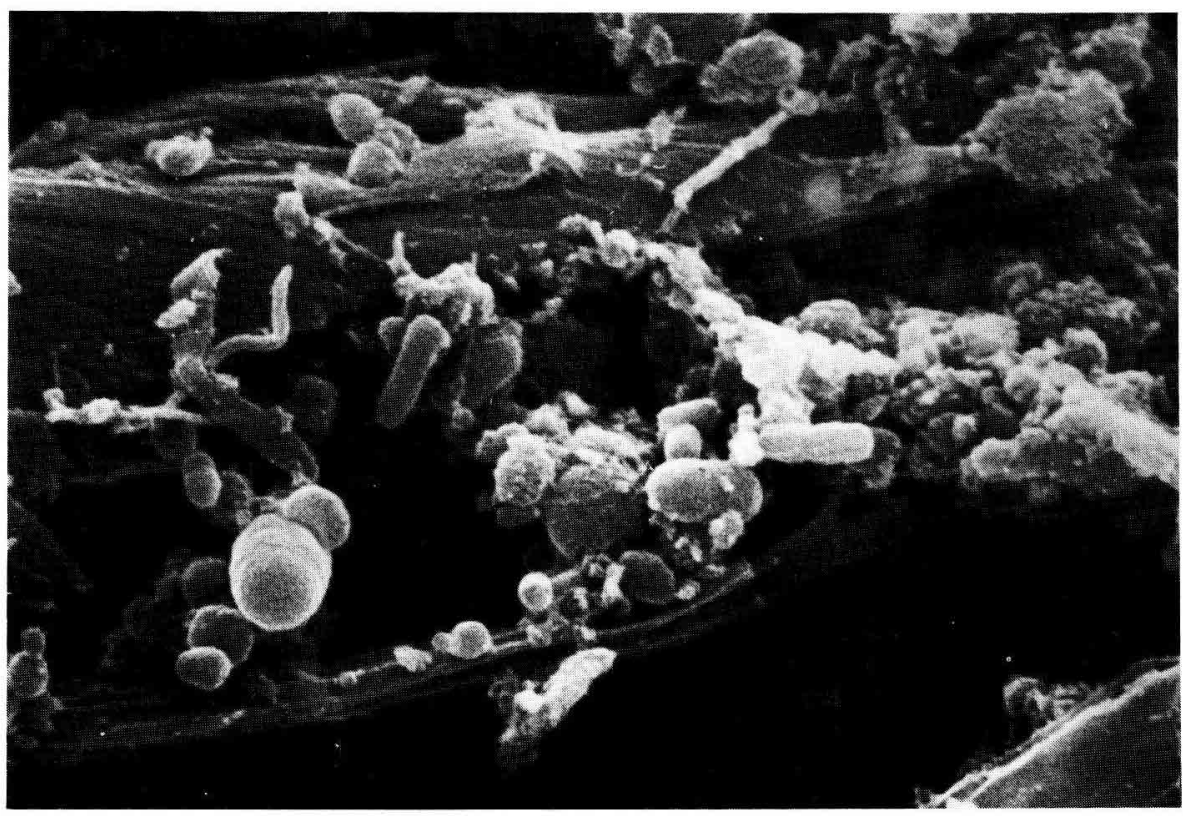

FIG. 3. - Vue de différentes bactéries pénétrant dans une particule végétale en cours de digestion dans le rumen. $6 \times 8400$ ) (Photo B. Gaillard, Laboratoire de Microbiologie, I.N.R.A.).

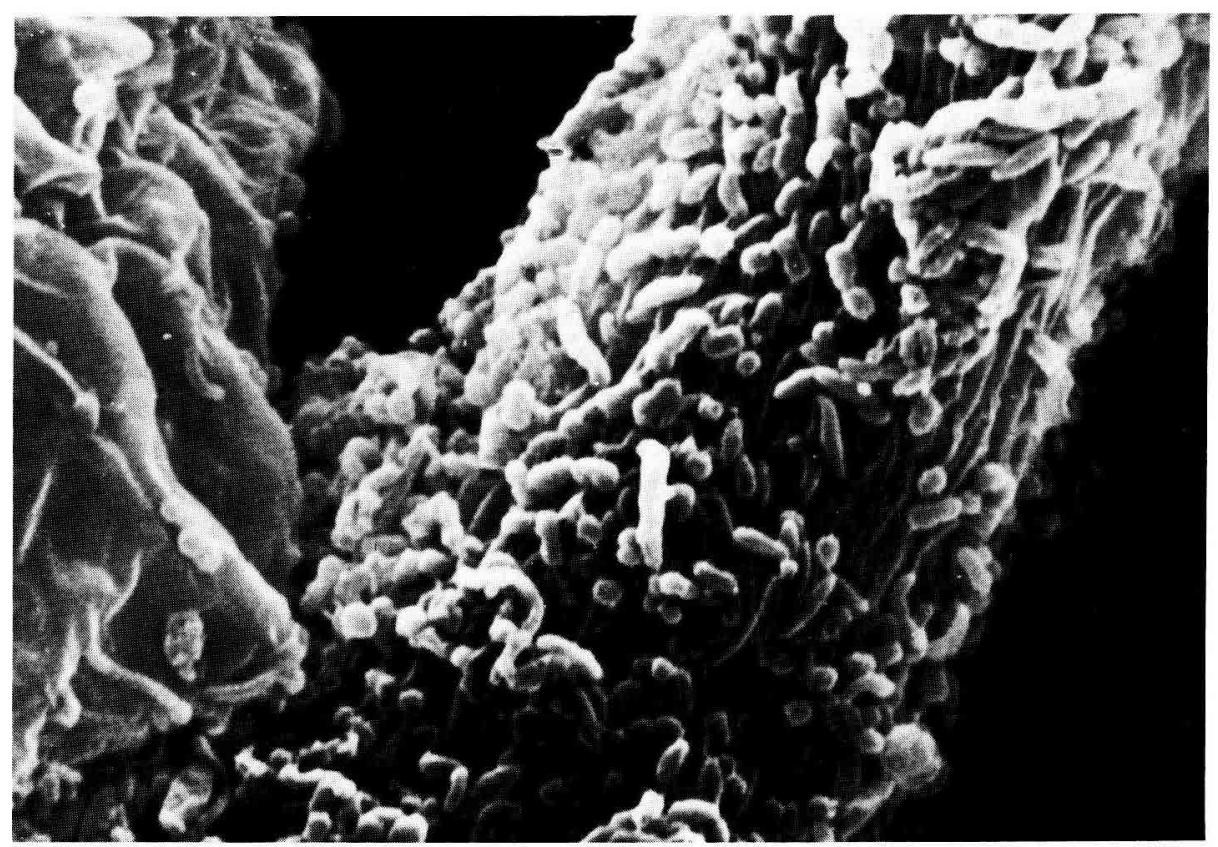

FIG. 4. - Vue de différentes bactéries fixées sur une cellule de l'assise des sabliers de la pellicule de soja ayant séjourné 48 heures dans le rumen. $(\times 4200)$ (Photo E. Grenet et P. Barry). 
1980). Dans certains cas, cette structure est très complexe et très extensive et les bactéries vivent à l'état de colonie à l'intérieur de cette structure avec les cellules soeurs parfaitement identiques (Cheng et Costerton, 1980). Ce glycocalyx pourrait avoir un rôle protecteur contre les bactériophages ou d'autres agents antibactériens (Ogimoto et Imai, 1981). Lorsque I'on considère la cellule bactérienne avec son glycocalyx, on peut distinguer plusieurs centaines de types morphologiques différents dans le rumen (Ritchie, communication personnelle).

Bactéries attachées aux particules alimentaires (fig. 3, 4 et 5). Bien que mises en évidence depuis longtemps (Baker et Nasr, 1947), ces bactéries ont constitué le centre d'intérêt de nombreuses études au cours de ces dix dernières années avec le développement de la microscopie électronique à transmission ou à balayage (Minato et al., 1966 ; Dinsdale et al., 1978 ; Minato et Suto, 1979, 1981 ; Akin, 1980 ; Cheng et al., 1980 ; Latham, 1980 ; Akin et Barton, 1983). Selon Minato et al. (1966), environ la moitié de la population bactérienne serait attachée aux particules végétales et pour Forsberg et Lam (1977) $75 \%$ de I'ATP microbien détecté dans le rumen serait fixé à des particules. Cette adhésion se fait sur les parois végétales (fig. 3 ) et notamment sur les tissus cellulosiques et concerne principalement les bactéries dégradant les polymères pariétaux (fig. 5). Les bactéries amylolytiques adhèrent également aux grains d'amidon (Minato et Suto, 1979). L'adhésion se fait par l'intermédiaire du glycocalyx (Cheng et Costerton, 1980). L'activité métabolique (Williams, 1982) et la composition chimique (Merry et Mc Allan, 1983) seraient différentes de celles des bactéries libres.

Bactéries adhérentes à la paroi du rumen (flore épimurale) (fig. 6). - Elles ont fait l'objet d'un nombre important d'études en microscopie électronique (Bauchop et al., 1975 ; Mc Cowan et al., 1978, 1980 ; Cheng et al., 1974, 1980 ; Dinsdale et al., 1980) mais peu ont été étudiées en culture (Dehority et Grubb, 1981 ; Mead et Jones, 1981). Ces bactéries sont fixées sur l'épithélium squameux stratifié par l'intermédiaire d'un glycocalyx polyholosidique qui présente les caractéristiques d'un polymère anionique. Un nombre limité de types morphologiques a été observé. Ce sont essentiellement des diplocoques, des coques et des bacilles Gram positif et anaérobies facultatifs (Cheng et Costerton, 1980), caractérisés par leur forte activité protéolytique (Dinsdale et al., 1980) et uréolytique (Mc Cowan et al., 1980 ; Dehority et Grubb, 1981). Ces bactéries seraient différentes du point de vue taxonomique de celles vivant librement dans le jus de rumen (Cheng et Costerton, 1980). Pour certains auteurs cependant, cette population serait très diversifiée (Bauchop et al., 1975) et composée en grande partie d'espèces anaérobies strictes (Dehority et Grubb, 1981 ; Mead et Jones, 1981). Cette population bactérienne semble être plus indépendante de la nature de l'alimentation que la population libre. Elle se maintient chez des animaux nourris artificiellement avec des infusions liquides de nutriments dans le rumen (Dinsdale et al., 1980).

FIG. 5. - Attaque et digestion d'une paroi cellulaire végétale $(\rightarrow$ / par les bactéries (*) dans le rumen du mouton. Microscope électronique à transmission ( $\times 30000)$ (Photo J. Senaud, J. Grain, J. Bohatier, U.A. associée au CNRS n 138, Université Clermont II). 


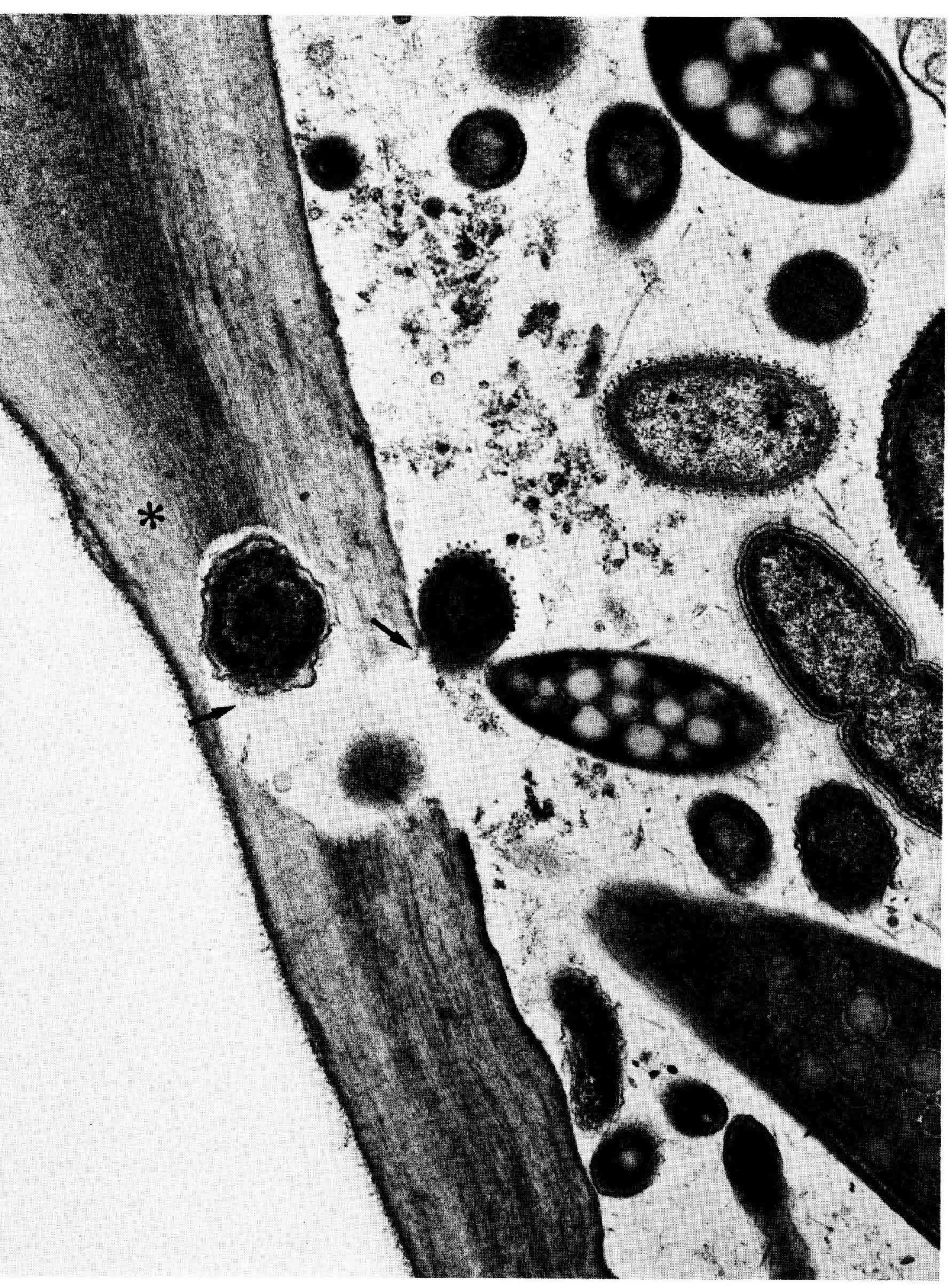


597.

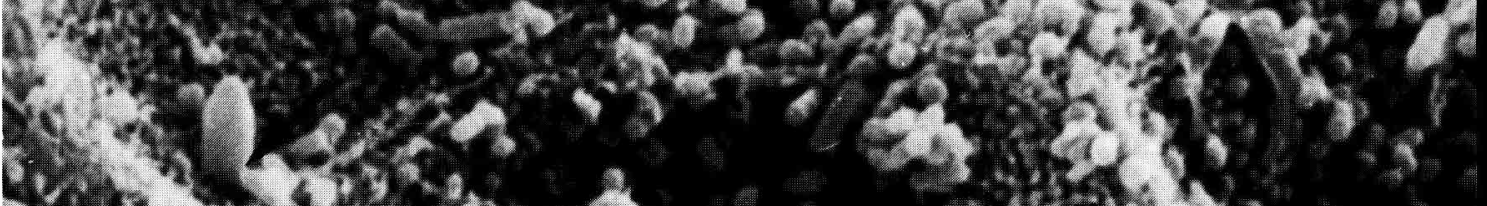

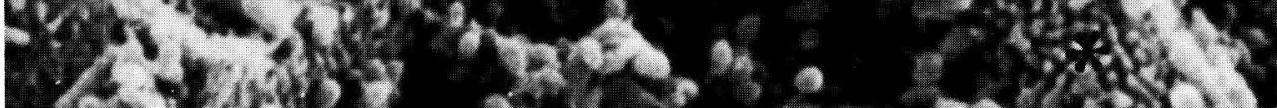

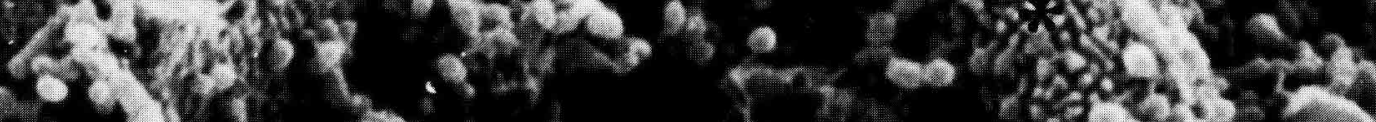

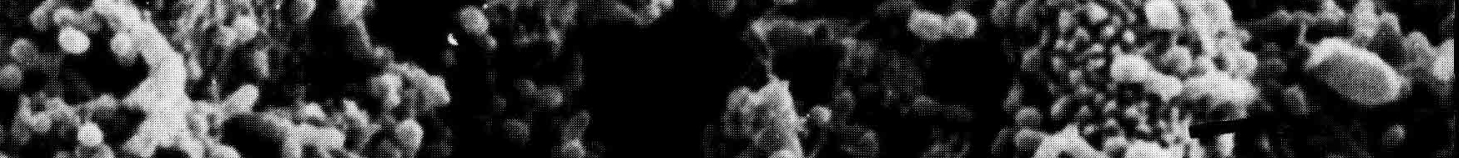

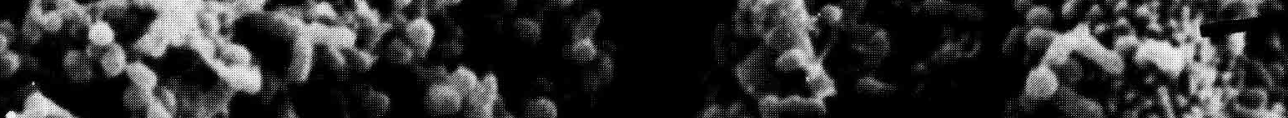

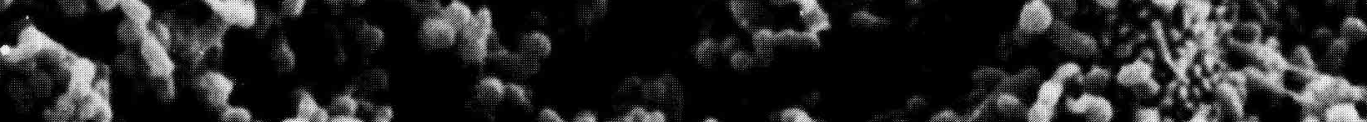

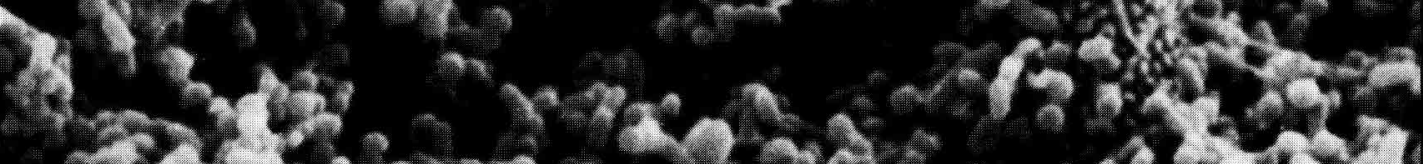

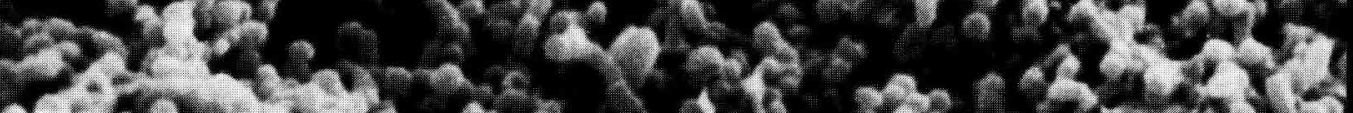

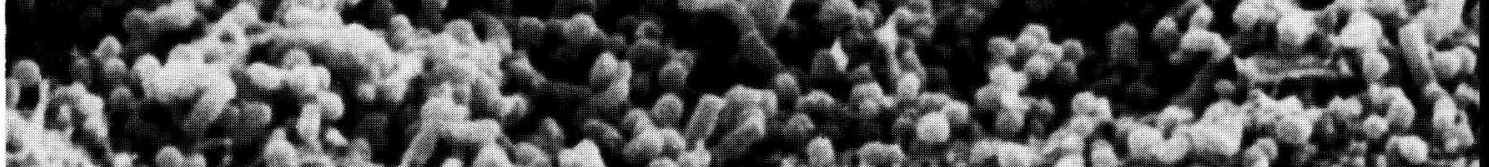

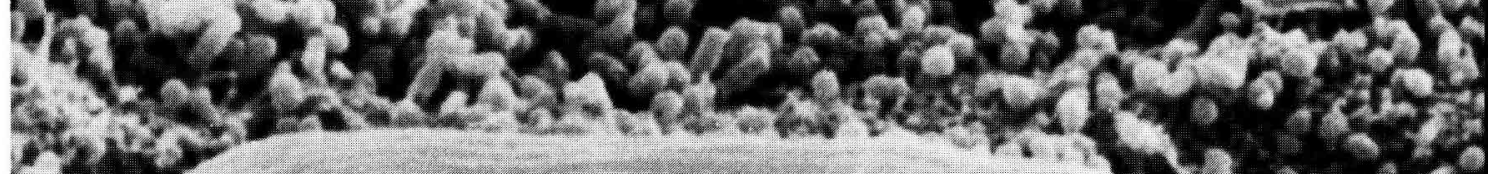

(2.

a

1

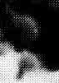

If $>2$

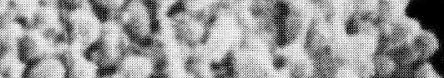

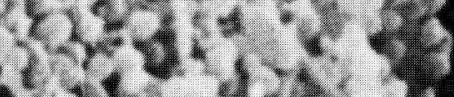

C.

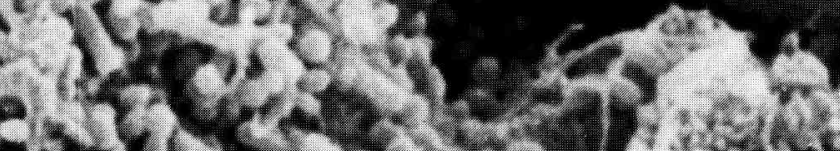

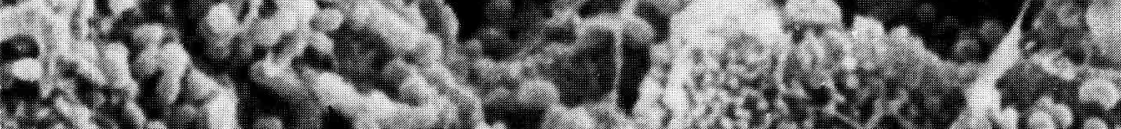

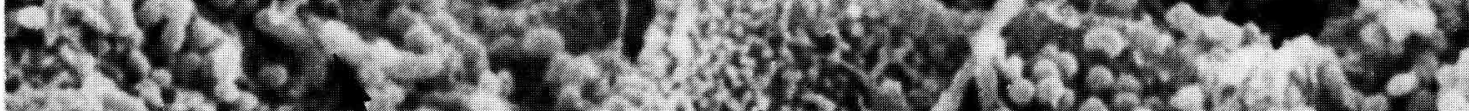

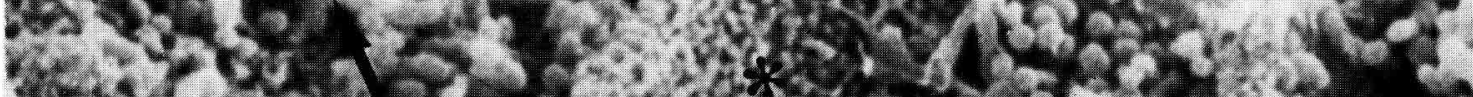

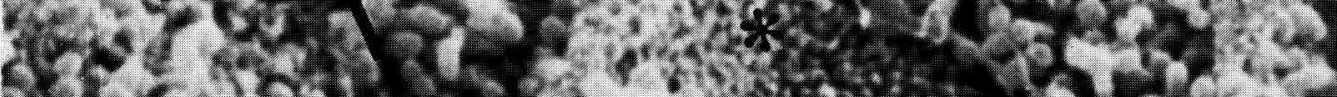

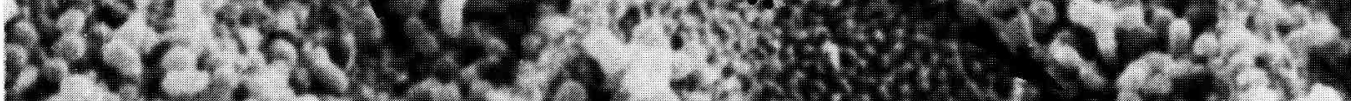

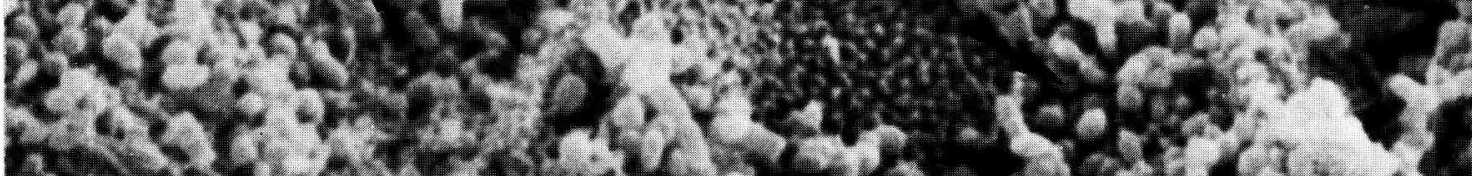

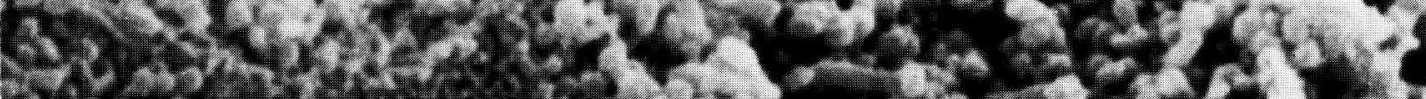

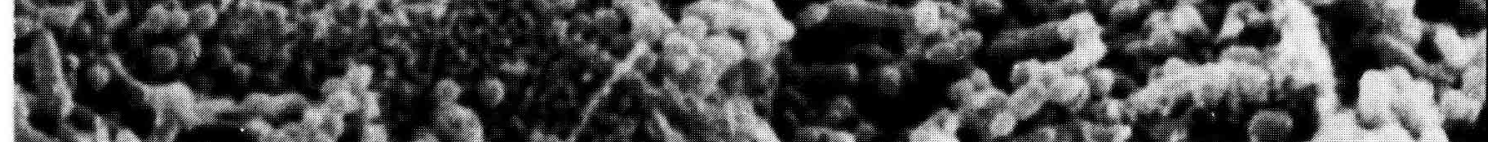


Le rôle joué par ces bactéries est très important : leurs fonctions principales seraient : 1) d'hydrolyser l'urée qui diffuse à travers la paroi du rumen (Cheng et Costerton, 1980 ; Wallace et al., 1979) ; 2) de dégrader les cellules épithéliales fortement kératinisées provenant de la desquamation de la muqueuse du rumen (Dinsdale et al., 1980; Mc Cowan et al., 1978, 1980) ; 3) d'éliminer l'oxygène qui diffuse à travers la paroi du rumen depuis la voie sanguine. En plus des protéases et des uréases, ces bactéries seraient également riches en phosphatase alcaline (Fay et al., 1979).

Bactéries adhérentes aux protozoaires. - Imai et Ogimoto (1978) ont mis en évidence une population bactérienne relativement abondante, vivant attachée à la surface des protozoaires lessentiellement des genres Eudiplodinium, Diplodinium, Entodinium, Epidinium). Cette population pourrait atteindre de 1 à $10 \%$ de la flore totale du rumen. Le nombre de bactéries fixées sur chaque cilié dépend évidemment de la taille de celui-ci, en moyenne 250 bactéries sont attachées à la surface d'un protozoaire. La majeure partie des bactéries adhérentes a été identifiée comme étant Streptococcus bovis, Ruminococcus albus (Imai et Ogimoto, 1978), et des bactéries méthanogènes (Krumholz et al., 1983).

\section{B) Les protozoaires}

Les protozoaires ciliés sont généralement libres dans le liquide de rumen mais certains se fixent également aux particules végétales. Ce sont les genres Epidinium (Amos et Akin, 1978 ; Bauchop et Clarke, 1976 ; Orpin et Letcher, 1978 ; Grain et Senaud, 1984) et /sotricha et Dasytricha (Orpin et Hall, 1977). I. prostoma et 1 . intestinalis présentent un chimiotactisme vis-à-vis des sucres solubles libérés par la dégradation des polyholosides végétaux et adhèrent aux particules alimentaires par l'intermédiaire d'un organelle spécialisé (Orpin et Letcher, 1978). Ces ciliés peuvent également se fixer sur la paroi du réseau et migrer ensuite vers le rumen après la prise de nourriture par le Ruminant sous l'action de stimuli chimiques provenant de la ration (Abe et al., 1981). Cet attachement des protozoaires aux particules végétales peut expliquer leur sequestration et leur rétention dans le rumen, ainsi que leur survie dans cet organe en dépit d'un temps de génération plus long que le temps de renouvellement du liquide du rumen (Bauchop et Clarke, 1976).

\section{C) Les champignons}

Les champignons sont également étroitement associés aux particules alimentaires (Bauchop, 1981 ; Orpin, 1984). Les zoospores, grâce à un chimiotactisme prononcé pour de nombreux glucides végétaux, s'attachent puis s'enkystent et germent sur les tissus végétaux endommagés par la mastication, et dans les stomates (Orpin, 1984).

FIG. 6. - Vue de la paroi du sac ventral du rumen du mouton montrant les micropapilles ( *), les bactéries adhérentes $(\rightarrow)$ et un cilié entodiniomorphe $(\bullet)$. Microscopie à balayage ( $\times 6000$ ) (Photo J. Senaud et J. Bohatier, U.A. associée au CNRS $n^{0} 138$, Université de Clermont II).

Reproduction, Nutrition, Développement $n^{\circ} 4$ B-1985. -2. 


\section{Quelques caractéristiques du fermenteur rumen}

\section{1) La dégradation des glucides des parois des cellules végétales}

Grâce à un extraordinaire équipement enzymatique, la population microbienne du rumen dégrade les constituants glucidiques (cellulose, hémicelluloses, substances pectiques) des parois végétales en oses qui sont ensuite fermentés en anaérobiose selon des voies actuellement.bien connues (fig. 7). L'importance de

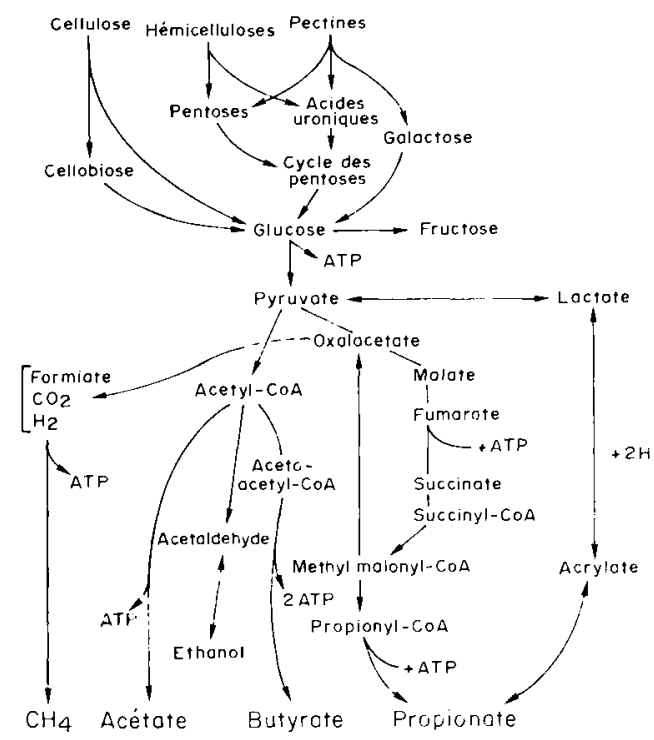

FIG. 7. - Schéma du métabolisme des glucides pariétaux dans le rumen (d'après Van Soest, 1982).

cette dégradation est extrêmement variable : de 80 à $90 \%$ pour la fraction pariétale d'un aliment très peu lignifié (herbe jeune) à 40-50\% pour une plante âgée et riche en lignine (paille). Les principaux facteurs responsables de ces variations sont :

- la nature des glucides pariétaux, étroitement liée à l'origine botanique de la plante, à l'organe (tige ou feuille) et au tissu considéré (parenchyme, sclérenchyme), donc au stade de végétation (tabl. 3) ;

TABLEAU 3

Digestibilité des constituants glucidiques des parois végétales (p. 100).

\begin{tabular}{|c|c|c|c|c|c|c|}
\hline & \multicolumn{2}{|c|}{ Trèfle } & \multicolumn{2}{|c|}{ Ray-grass } & \multicolumn{2}{|c|}{ Dactyle } \\
\hline & 1 mois & 2 mois & 1 mois & 2 mois & 1 mois & 2 mois \\
\hline $\begin{array}{l}\text { Hémicelluloses } \\
\text { Cellulose }\end{array}$ & $\begin{array}{l}77,7 \\
86.9\end{array}$ & $\begin{array}{l}66,0 \\
75,0\end{array}$ & $\begin{array}{l}79,7 \\
89,1\end{array}$ & $\begin{array}{l}63,6 \\
705\end{array}$ & $\begin{array}{l}75,6 \\
822\end{array}$ & $\begin{array}{l}64,0 \\
730\end{array}$ \\
\hline
\end{tabular}


- la teneur en lignine du végétal, principal facteur explicatif des variations de digestibilité avec, mais à un degré moindre, divers autres constituants (groupements acétyles, silice, cutine) (fig. 8) (Jarrige, 1980b) ;

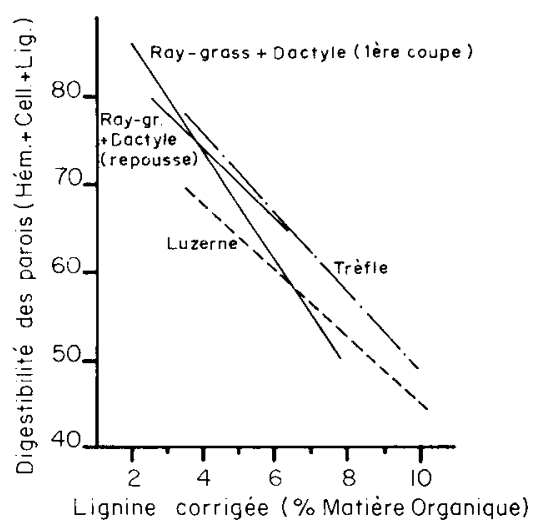

FIG. 8. - Relation entre la digestibilité des parois et leur teneur en lignine (Jarrige, $1980 \mathrm{~b}$ ).

- la présentation physique de l'aliment et d'une façon générale la nature des traitements technologiques (broyage, agglomération, action des agents chimiques ou biologiques) qu'on peut lui appliquer. Ces facteurs peuvent modifier le temps de séjour des particules alimentaires dans le rumen, donc le temps de contact enzymes-substrat, accroître la surface pariétale accessible aux enzymes et réduire le nombre et la force des liaisons glucides-lignine qui limitent leur action ;

- les autres constituants de la ration, en particulier la nature et la quantité de l'azote et des minéraux disponibles pour les microbes qui conditionnent directement leur activité et donc leur potentiel enzymatique.

La population microbienne du rumen tire de la fermentation des oses provenant de I'hydrolyse des glucides pariétaux, l'énergie (A.T.P.) et le carbone qui lui sont nécessaires pour son entretien, sa croissance et sa prolifération. Les produits de déchets de cette fermentation sont un mélange d'acides organiques à courte chaîne, dits acides gras volatils, essentiellement acétique, propionique et butyrique, et des gaz (gaz carbonique et méthane). Les produits intermédiaires (acides sućcinique, lactique...) sont généralement utilisés par les microbes au fur et à mesure de leur formation. Contrairement à l'animal monogastrique pour lequel la principale source d'énergie est le glucose, le ruminant trouve la majeure partie de l'énergie dont il a besoin dans les acides gras volatils issus de la dégradation des glucides. Ils peuvent lui fournir de 65 à $75 \%$ de l'énergie absorbée (cf. Vermorel, 1978), le reste provenant des acides aminés, des acides gras longs et dans certains cas (rations riches en amidon) du glucose (tabl 4). Le propionate est utilisé préférentiellement au niveau du foie pour fournir le glucose nécessaire au ruminant et que celui-ci ne peut trouver qu'en quantité généralement très faible à partir de l'hydrolyse des glucides des aliments. La néoglucogenèse est donc un phé-

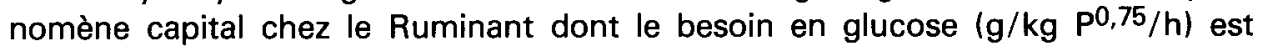
comparable à celui déterminé chez le monogastrique. L'activité des enzymes de la 
néoglucogenèse (pyruvate carboxylase, phosphoenolpyruvate carboxykinase) est d'ailleurs différente et considérablement plus importante dans la mitochondrie chez le Ruminant que chez le Monogastrique (Ballard et al., 1969). La part du propionate non transformée en glucose et les autres acides gras volatils sont utilisés pour couvrir les dépenses énergétiques d'entretien et de production de l'organisme.

TABLEAU 4

Origine et répartition ( $\rho$. 100) de l'énergie absorbée dans le tube digestif du ruminant

\begin{tabular}{lcccc}
\hline & $\begin{array}{c}\text { Acides gras } \\
\text { Volatils }\end{array}$ & Glucose & $\begin{array}{c}\text { Acides } \\
\text { aminés }\end{array}$ & $\begin{array}{c}\text { Acides gras } \\
\text { longs }\end{array}$ \\
\cline { 2 - 5 } $\begin{array}{l}\text { Foin de pré } \\
\begin{array}{l}\text { Ration mixte } \\
(50-50)\end{array}\end{array}$ & 78 & 0,2 & 16 & 5 \\
$\begin{array}{l}\text { Ration riche } \\
\text { en maïs }(70 \%)\end{array}$ & 65 & 3 & 23 & 9 \\
\hline
\end{tabular}

(d'après Vermorel, 1978)

En définitive, la cellulolyse chez les ruminants est le mécanisme central dans la digestion des aliments. Malgré les différents facteurs qui limitent la dégradabilité des glucides pariétaux dans le rumen, les ruminants sont, de tous les herbivores, ceux qui utilisent le plus efficacement ces composés. Ils possèdent à l'évidence une supériorité sur l'ensemble de tous les mammifères dans la mesure où les sources alimentaires de glucides pariétaux - essentiellement l'appareil végétatif des plantes fourragères - n'entrent pas en concurrence ni avec l'alimentation des autres animaux à intérêt zootechnique ni a fortiori avec celle de l'homme.

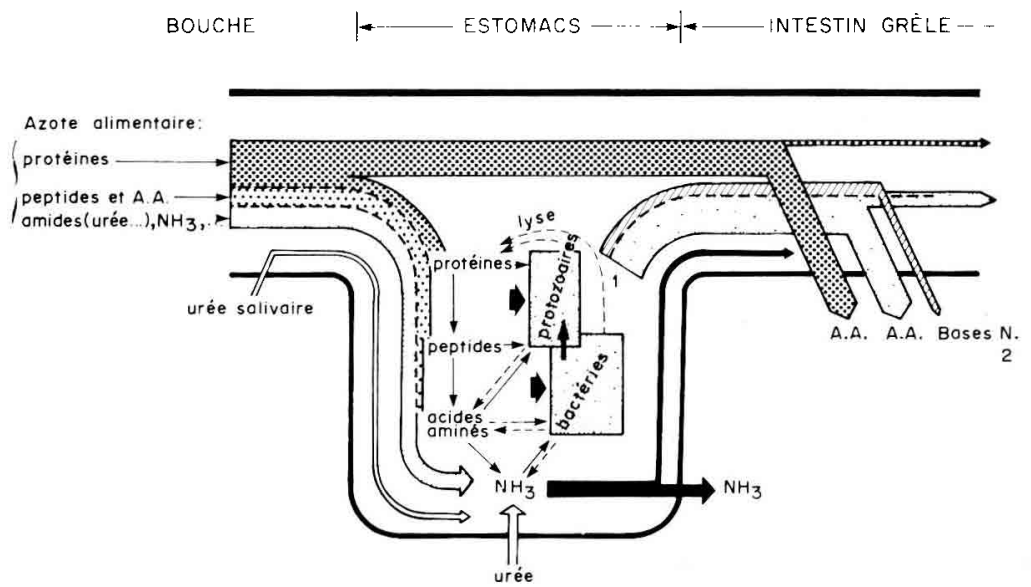

FIG. 9. - Schémà de la dégradation et de l'utilisation des matières azotées dans le rumen chez le ruminant (d'après Jarrige, 1978). 1) L'azote microbien se trouve approximativement pour $80 \%$ sous forme de protéines vraies et pour $20 \%$ sous forme d'acides nucléiques. 2) Les bases azotées proviennent de la digestion de ces derniers.

PeAzote microbien : Wllfe : Fraction nucléique de l'azote microbien. 


\section{2) L'utilisation de l'azote non protéique}

Une autre particularité du fermenteur rumen est sa capacité d'incorporer l'azote non protéique dans les protéines bactériennes qui constituent une source importante d'acides aminés pour satisfaire les besoins en azote de l'animal. Cette caractéristique permet au ruminant de tirer parti des sources d'azote telles que l'urée ou les sels ammoniacaux que les autres espèces domestiques ne peuvent pas utiliser. C'est un second exemple de l'indépendance du ruminant par rapport à l'homme ou aux autres mammifères eu égard à la satisfaction de ses besoins alimentaires.

Les différentes étapes de la dégradation et du métabolisme de l'azote chez le ruminant sont représentées sur la figure 9. La dégradation des protéines alimentaires par les enzymes des bactéries et des protozoaires du rumen conduit à la formation d'ammoniaque qui va servir ensuite aux bactéries pour assurer leur propre synthèse protéique. La partie d'ammoniaque non utilisée pour cette protéosynthèse sera absorbée par la paroi du rumen, transportée dans le foie et éliminée par le rein sous forme d'urée. Une partie de celle-ci sera recyclée dans le rumen par voie sanguine et salivaire; enfin, une faible part d'ammoniaque transitera vers l'intestin grêle. La fraction des protéines alimentaires non dégradées par les microbes du rumen sera digérée dans l'intestin grêle selon des mécanismes que l'on estime voisins de ceux qui sont décrits chez le monogastrique.

L'azote ammoniacal constitue donc le substrat préférentiel pour la plupart des bactéries qui l'utilisent à raison de 50 à $80 \%$ de l'azote fixé pour la constitution de leurs propres protéines. Certaines espèces bactériennes (Ruminococcus, Bacteroides, Méthanobrevibacter) n'utilisent pas l'azote des peptides ou des acides aminés. D'une façon générale, les acides aminés ne sont pas nécessaires pour la protéosynthèse bactérienne. Cependant, celle-ci est largement stimulée quand on associe des acides aminés à une source d'azote non protéique. Ceci s'explique par la formation, lors de la fermentation des acides aminés, d'acides gras ramifiés à courte chaîne (isobutyrate, isovalérate, 2-méthyl butyrate), qui sont nécessaires pour la croissance de certaines bactéries, telles que les bactéries cellulolytiques.

La concentration en ammoniaque dans le rumen peut varier de 2 à 40 mmoles/I mais on estime à 4-5 mmoles/l la teneur nécessaire pour que la production de protéines bactériennes soit maximum. En fait, ces valeurs sont très variables selon les auteurs et dépendent de nombreux facteurs (composition de la ration, nature et importance de la population bactérienne,...). La croissance microbienne n'est pas inhibée par des fortes teneurs en ammoniaque (jusqu'à 60 $\mathrm{mmol} / \mathrm{l}$ de contenu de rumen), ce qui est bien supérieur à ce qu'un ruminant peut tolérer.

Les mécanismes de transformation de l'ammoniaque en acides aminés à l'intérieur des bactéries du rumen ont été relativement bien étudiés ; un certain nombre d'enzymes a été mis en évidence, qui correspond d'ailleurs à celui qui est connu chez d'autres bactéries (Hespell, 1983). La glutamine synthétase et la glutamate deshydrogénase semblent les deux premières enzymes impliquées dans ces voies métaboliques. Certaines propriétés de ces enzymes diffèrent cependant d'une espèce à l'autre, pour différentes raisons (teneur en ammoniaque du milieu, vitesse de croissance différente...). Une fois dans les bactéries (les mécanismes 
de passage de $\mathrm{NH}_{3}$ à travers la paroi ne sont pas encore connus ; Hespell, 1983), l'ammoniaque est transformé en groupement amide de la glutamine ou (et) de I'asparagine (Smith, 1979). Ces groupements sont utilisés pour l'amination de l' $\alpha$ cétoglutarate en glutamate. Vient ensuite la synthèse de l'alanine et de l'aspartate, puis celle des autres acides aminés a lieu par transfert des groupes aminés sur d'autres chaînes carbonées. L'ensemble de ces acides aminés est alors utilisé pour la formation des protéines et la synthèse des acides nucléiques.

Les protozoaires, à l'inverse des bactéries, ne peuvent assurer leur croissance à partir de l'azote non protéique et doivent utiliser des acides aminés qu'ils trouvent au moins en faible quantité sous forme libre et vraisemblablement dans les corps bactériens qu'ils ingèrent (Coleman, 1967 a et b) et dans certaines protéines végétales peu dégradées telles que celles des chloroplastes.

L'importance de la synthèse microbienne dans le rumen est considérable. La part de l'azote d'origine microbienne qui entre dans l'intestin grêle représente environ la moitié de l'azote total (tabl. 5). Dans certains cas, cette proportion peut être beaucoup plus importante, si la dégradation des protéines alimentaires dans le rumen est élevée ou si elles ne constituent qu'une faible part de la ration. La quantité de protéines microbiennes synthétisée dans le rumen dépend de très nombreux facteurs parmi lesquels la quantité d'énergie disponible (A.T.P.) est le plus important. Lorsque les besoins en énergie sont couverts, la quantité d'azote microbien qui quitte le rumen peut être supérieure à la quantité d'azote ingéré, car les bactéries peuvent utiliser l'ammoniac provenant de l'urée recyclée dans le rumen à travers la paroi et par la salive. Ce phénoméne de recyclage, très important chez le ruminant et en particulier chez certaines espèces (chèvres) ou chez les camélidés, permet d'économiser dans certaines conditions physiologiques (besoins azotés élevés ou insuffisance des apports azotés) une quantité considérable d'azote (jusqu'à $80 \%$ de l'azote ingéré) qui serait éliminée sous forme d'urée par la voie urinaire.

TABLEAU 5

Digestion de l'azote chez le ruminant

\begin{tabular}{ccccc} 
Azote ingéré & & \multicolumn{2}{c}{ Azote duodénal } & microbien \\
$\%$ & $\mathrm{~g} / \mathrm{j}$ & $\begin{array}{c}\text { \% azote } \\
\text { ingéré }\end{array}$ & $\begin{array}{c}\text { alimentaire } \\
\%\end{array}$ \\
\hline 34,2 & 21,8 & 64 & 63 & 35 \\
22,8 & 23,4 & 103 & 52 & 44 \\
22,1 & 32,8 & 148 & 54 & 43 \\
17,0 & 16,6 & 98 & 96 & - \\
\hline
\end{tabular}

(données : Laboratoire de la Digestion des Ruminants, I.N.R.A.)

La substance microbienne ainsi formée quitte le rumen avec la fraction des aliments non digérée et sera hydrolysée dans l'intestin grêle. Dans des conditions normales d'alimentation, elle fournira au ruminant la majeure partie des acides aminés dont il a besoin grâce à sa bonne digestibilité (70\% pour les bactéries ; $80 \%$ pour les protozoaires) et à son équilibre satisfaisant en acides aminés sauf pour la méthionine et surtout I'histidine. II faut cependant signaler que la part des protozoaires qui quittent le rumen est faible. Ils peuvent représenter environ 10 à 
$15 \%$ de l'azote duodénal. De ce fait, leur contribution pour satisfaire les besoins en acides aminés du ruminant est probablement limitée.

Un des facteurs essentiels de la nutrition azotée du ruminant est donc l'aspect qualitatif et quantitatif de la protéosynthèse dans le rumen. Ceci explique le développement des travaux qui sont réalisés depuis une dizaine d'années, à la fois pour mesurer la quantité de protéines microbiennes synthétisées dans le rumen et pour étudier les différents facteurs de variation de l'efficacité de cette synthèse. Ces facteurs sont nombreux et ont trait aux différents aspects de la physiologie digestive dans le rumen. Nous citerons les principaux : nature et synchronisme des apports de l'énergie et de l'azote, rôle des protozoaires, des additifs (antibiotiques ionophores), et du temps de séjour des particules alimentaires, en renvoyant le lecteur aux revues qui ont été récemment publiées (Harrison et Mc Allan, 1980 ; Demeyer et Vervaeke, 1984 ; Smith, 1979 ; Hespell et Bryant, 1979). Nous ne développerons que les aspects concernant le rôle des macro et des oligoéléments dans la digestion microbienne, parce que les recherches dans ce domaine sont récentes et les résultats par conséquent encore peu connus.

\section{3) Eléments minéraux et digestion microbienne au niveau du rumen}

Macro-éléments. - Les macro-éléments exercent un rôle à la fois sur certaines propriétés physico-chimiques de l'environnement microbien (pouvoir tampon et pression osmotique du milieu, taux de renouvellement de la phase liquide) et sur le métabolisme propre des micro-organismes (Durand et Kawashima, 1980). Ainsi, l'addition de tampons minéraux au régime permet de limiter une chute trop rapide du $\mathrm{pH}$, conséquence de l'ingestion de régimes riches en amidon. Le maintien de la pression osmotique dans une zone favorable aux fermentations (200 à 280 mosmol $/ \mathrm{kg}$ ) est essentiellement dû aux ions minéraux ( $\mathrm{Na}, \mathrm{K}, \mathrm{PO}_{4}, \mathrm{Cl}, \mathrm{Mg}, \mathrm{Ca}$ ). Un accroissement du taux de renouvellement de la phase liquide, facteur favorisant l'efficacité de la protéosynthèse microbienne, peut être obtenu par incorporation de sels minéraux au régime; par contre, lorsque l'apport salivaire de phosphate est réduit par une subcarence du régime en phosphore, le taux de renouvellement s'abaisse (Durand et al., 1983).

Les macro-éléments se retrouvent associés aux composants essentiels de la cellule bactérienne tels que ribosomes $(P, S, K$ et $M g)$, matériel nucléaire $(P)$, membranes ( $\mathrm{P}, \mathrm{Mg}, \mathrm{Ca})$, parois $(\mathrm{P}, \mathrm{Mg}, \mathrm{Ca})$; ils sont nécessaires à la majorité des activités enzymatiques intracellulaires ou même extracellulaires telles que les activités amylasique et cellulasique qui sont stimulées par le calcium.

Les effets positifs de l'addition de macro-éléments à des milieux carencés ont été observés in vitro à la fois sur la croissance de cultures pures de bactéries du rumen ( $\mathrm{P}, \mathrm{Mg}, \mathrm{K}, \mathrm{Na}$ ) et sur l'activité cellulolytique $(\mathrm{S}, \mathrm{P}, \mathrm{Mg}, \mathrm{K}, \mathrm{Na}$ ) ou la protéosynthèse $(\mathrm{S}, \mathrm{P}, \mathrm{Mg}$ ) dans des milieux complexes de rumen. Cependant, l'estimation des besoins optimaux reste encore imprécise. L'incorporation de phosphore dans les corps microbiens (pour $80 \%$ dans les acides nucléiques et $10 \%$ dans les phospholipides) est fonction de la production d'acides gras volatils dans le milieu (600 mg P/mole d'AGV) et de l'intensité de la protéosynthèse. Les besoins s'élèveraient à 5-6 g de $\mathrm{P}$ par $\mathrm{kg}$ de matière organique fermentée (Durand et al., 1983). 
Le soufre, nécessaire à la synthèse de novo des acides aminés soufrés et des vitamines (thiamine, biotine), est particulièrement important pour la protéosynthèse à partir de l'azote non protéique (revue de Durand, 1984). in vivo, l'apport de soufre apparaît indispensable lorsque les aliments doivent être supplémentés par de l'azote non protéique ou dans le cas des fourrages pour lesquels les disponibilités de l'azote et du soufre sont faibles. Cependant, l'estimation quantitative des besoins doit tenir compte des pertes de sulfure au niveau du rumen. La réduction des sulfates en sulfures $\left(\mathrm{H}_{2} \mathrm{~S}\right)$ est très rapide, le nombre des bactéries sulfato-réductrices pouvant atteindre $10^{8} / \mathrm{ml}$ dans le milieu du rumen. Comme pour l'ammoniac, $\mathrm{H}_{2} \mathrm{~S}$ en excès (non utilisé pour la synthèse des acides aminés) est très rapidement absorbé à travers la paroi du rumen. Cependant, le recyclage du soufre est beaucoup plus réduit que celui de l'azote : aussi, deux à trois heures après le repas le milieu de rumen peut être carencé en soufre disponible.

L'apport salivaire en Mg et Ca étant faible, la couverture des besoins des micro-organismes dépendra des apports alimentaires et de leur disponibilité dans le milieu de rumen ; or, leur solubilité est relativement basse et dépendante du $\mathrm{pH}$. Lorsque les régimes sont subcarencés, en $\mathrm{Mg}$ notamment (taux inférieurs à $1 \mathrm{~g} / \mathrm{kg} \mathrm{MS}$ ), et lorsque le $\mathrm{pH}$ du rumen est élevé (fortes concentrations en ammoniac), les besoins des micro-organismes risquent de ne pas être couverts. Les concentıations de $\mathrm{Na}$ et $\mathrm{K}$ requises pour un bon déroulement des fermentations sont importantes (0,5-2 g/l). In vivo, l'apport salivaire de $\mathrm{Na}$ est généralement suffisant mais celui de $\mathrm{K}$ est plus limité. Cependant, le potassium alimentaire est très soluble au niveau du rumen et une carence ne pourra se manifester que pour des taux réduits de $\mathrm{K}$ dans l'aliment (inférieurs à $4 \mathrm{~g} / \mathrm{kg} \mathrm{MS}$ ).

Oligo-éléments. - De nombreuses activités enzymatiques bactériennes sont régulées par des oligo-éléments tels que le fer (Fe), le manganèse $(\mathrm{Mn})$, le zinc $(\mathrm{Zn})$, le cobalt ( $\mathrm{Co})$, le molybdène ( $\mathrm{Mo}$ ), le sélénium (Se), le nickel ( $\mathrm{Ni}$ )... Certains oligo-éléments rentrent aussi dans la composition d'éléments cellulaires comme les ribosomes ou les membranes. Les teneurs en oligo-éléments des microorganismes du rumen sont généralement bien supérieures à celles des aliments que l'animal ingère. En effet, les parois des bactéries sont capables de fixer des oligo-éléments par des liaisons qui sont plus ou moins réversibles en milieu acide. Aussi, les besoins en oligo-éléments des bactéries ne peuvent pas être déduits de leurs concentrations dans la masse microbienne.

Des études in vitro ont montré que l'activité cellulolytique est stimulée par des apports d'oligo-éléments ; de même, la croissance des protozoaires en culture de longue durée peut être accrue par un apport de $\mathrm{Zn}$ ou de Co. Cependant, l'ampleur de la réponse est souvent variable; elle peut en effet être influencée par la composition minérale du milieu, notamment par la concentration en ions sulfures $\left(S^{2-}\right)$. Une interaction Mo-S a été mise en évidence : l'effet stimulant de Mo sur la cellulolyse n'est plus observé après addition de sulfate et inversement l'addition de Mo accroît les besoins en soufre. Les thiomolybdates qui se forment dans le rumen à partir de $\mathrm{S}^{2-}$, sont probablement inutilisables par la microflore. Les régimes pauvres en certains oligoéléments provoquent un ralentissement des fermentations dans le rumen. Avec un régime à base de paille, la digestion de la cel- 
lulose est stimulée par un apport de Co et de $\mathrm{Cu}$ chez le bovin, et la synthèse de vitamine $B_{12}$ est accrue par addition de Co lorsque les animaux consomment un foin pauvre. Cependant, un apport en quantité excessive d'oligo-éléments peut inhiber les fermentations microbiennes in vitro. L'activité cellulolytique est particulièrement sensible car les cellulases sont extra-cellulaires donc plus susceptibles d'être inhibées que les enzymes intra-cellulaires (uréase par exemple) protégées par les parois. La croissance des protozoaires est plus affectée que celle des bactéries comme cela a été démontré pour le cuivre, le zinc et le cobalt.

In vivo, la toxicité de ces éléments envers la digestion microbienne est mal connue. Elle dépend des nombreux facteurs qui affectent la solubilité des éléments dans le milieu du rumen mais aussi du potentiel d'adaptation de la microflore, phénomène connu pour les bactéries du sol. En général, la présence d'un oligo-élément en excès sélectionne les espèces ou souches bactériennes capables de lier l'élément sur leurs parois ou de produire des capsules glucidiques qui l'immobilisent. Les protozoaires apparaissent moins aptes à s'adapter car ils absorbent rapidement les éléments dans leur endoplasme comme cela a été démontré pour le zinc en micro-analyse aux rayons $X$.

\section{Conclusions}

Le rumen est un fermenteur anaérobie qui permet d'utiliser efficacement les glucides des parois des cellules végétales et l'azote non protéique pour satisfaire tout ou partie des besoins en énergie et en acides aminés de l'animal. Ces deux caractéristiques confèrent aux ruminants un avantage évident pour valoriser des ressources alimentaires peu ou pas utilisables par les autres mammifères domestiques. En outre, le fermenteur “ rumen " s'intègre dans l'animal à un ensemble de fonctions qui font que son efficacité est, jusqu'à présent, bien supérieure à celle des fermenteurs in vitro (ou digesteurs), conçus pour tirer parti des matériaux lignocellulosiques. C'est ce que Hungate soulignait en 1979, en écrivant : « le ruminant peut être considéré comme une unité de fermentation qui collecte elle-même les substrats à dégrader, les transfère dans la chambre de fermentation, controle le temps de séjour, absorbe continuellement les produits terminaux de la fermentation et les transforme en substances immédiatement utilisables " (lait, viande, ...).

Cependant, ce fermenteur a des limites. Certaines lui sont imposées par l'anaérobiose. C'est le cas de la synthèse microbienne qui est moins abondante en condition anaérobie qu'aérobie. D'autres sont liées à la connaissance insuffisante des mécanismes de la dégradation des aliments (cellulolyse et protéolyse en particulier), des besoins nutritionnels des bactéries et des protozoaires, des facteurs de variation de l'activité microbienne... L'approfondissement des recherches dans ces différents domaines devrait permettre de repousser ces limites et d'améliorer ainsi le rendement de ce fermenteur. 


\section{Références}

ABE M., IRIKI T., TOBE N. SHIBUI H., 1981. Sequestration of holotrich protozoa in the reticulorumen of cattle. Appl. environ. Microbiol, 41, 758-765.

ABOU AKKADA A. R., HOWARD B. H., 1962. The biochemistry of rumen protozoa 5 . The nitrogen metabolism of Entodinium. Biochem J., 82, 313-320.

AKIN D. E., 1980. Evaluation by electron microscopy and anaerobic culture of types of rumen bacteria associated with digestion of forage cell walls. Appl. environ. Microbiol., 39, 242-252.

AKIN D. E., BARTON F. E., 1983. Rumen microbial attachment and degradation of plant cell walls. Fed. Proc., 42, 114-122.

AMOS H. E., AKIN D. E., 1978. Rumen protozoal degradation of structurally intact forage tissues. Appl. environ. Microbiol., 36, 513-522.

BAKER F., NASR H., 1947. Microscopy in the investigation of starch and cellulose breakdown in the digestive tract. J. roy. Microsc. Soc., 67, 27-42.

BALLARD F. J., HANSON R. W., KRONFELD D. S., 1969. Gluconeogenesis and lipogenesis in tissue from ruminant and non-ruminant animals. Fed. Proc., 28, 218-231.

BAUCHOP T., 1977. Foregut fermentation, 223-250. In CLARKE R.T.J., BAUCHOP T., Microbial ecology of the gut. Acad. Press. New-York.

BAUCHOP T., 1979. Rumen anaerobic fungi of cattle and sheep. Appl. environ. Microbiol., 38, 148-158.

BAUCHOP T., 1981. The anaerobic fungi in rumen fibre digestion. Agri. environ., 6, 339-348.

BAUCHOP T., CLARKE R. T. J., 1976. Attachment of the ciliate Epidinium crawley to plant fragments in the sheep rumen. Appl. environ. Microbiol., 32, 417-422.

BAUCHOP T., CLARKE R. T. J., NEWHOOK J. C., 1975. Scanning electron microscope study of bacteria associated with the rumen epithelium of sheep. Appl. Microbiol., 30, 668-675.

BONHOMME A., 1973. Contribution à l'étude de la physiologie des ciliés entodiniomorphes endocommensaux des ruminants et des équidés. Th. Doct. d'Etat. Univ. Reims.

BONHOMME-FLORENTIN A., 1975. Activité cellulolytique des ciliés entodinomorphes. J. Protozool., 22. 445-451.

BONHOMME A., FONTY G., WEBER M., ROBIC J., 1983. Activité cellulolytique de Polyplastron multivesiculatum. J. Protozool., 30, 63A.

BRYANT M. P., 1959. Bacterial species of the rumen. Bacteriol. Rev., 23, 125-153.

BRYANT M. P., 1977. Microbiology of the rumen, 287-304. In SIVENSON M. J., Duke's physiology of domestic animals. 9th ed. Cornell Univ. Press.

CHENG K. J., COSTERTON J. W., 1980. Adherent rumen bacteria - their role in the digestion of plant material, urea and epithelial cells, 227-250. In RUCKEBUSCH Y., THIVEND P., " Digestive physiology and metabolism in ruminant ". MTP Press, Lancaster.

CHENG K. J., Mc COWAN R. P. COSTERTON J. W., 1974. Adherent epithelial bacteria in ruminants and their roles in digestive tract function. Am. J. clin. Nutr., 32, 139-148.

CHENG K. J., Mc COWAN R. P., COSTERTON J. W., 1980. Distribution and enzyme activity of the bacterial population adherent to the epithelium of the bovine rumen. Abstr. Annu. Meet., Agri. Can. Res. Stat. Lethbridge, Alberta and Univ. of Calgary.

CHURCH D. C., 1975. Digestive physiology and nutrition of ruminants. Vol. 1 Digestive physiology, 2nd ed., O and B. Books. Inc, Corvallis, Oregon.

COLEMAN G. S., 1967a. The metabolism of free amino acids by washed suspensions of the rumen ciliate Entodinium Caudatum. J. gen. Microbiol., 47, 433-447.

COLEMAN G. S., 1967b. The metabolism of amino acids of Escherichia Coli and other bacteria by the rumen cilate Entodinium Caudatum. J. gen. Microbiol., 47, 449-464.

COLEMAN G. S., 1975. The interrelationship between rumen ciliate protozoa and bacteria, 149-164. In Mc DONALD I. W., WARNER A. C. I., "Digestion and metabolism in the ruminant ". The Univ. New England Publ. Unit, Armidale.

COLEMAN G. S., 1980. Rumen ciliate protozoa, 121-173. In LUMSDEN W. H. R., MULLER R., BAKER J. R. Advances in parasitology, Vol. 18, Acad. Press, London. 
DEHORITY B. A., GRUBB J. A., 1981. Bacterial population adherent to the epithelium on the roof of the dorsal rumen of sheep. Appl. environ. Microbiol., 41, 1424-1427.

DEMEYER D. I., 1981. Rumen microbes and digestion of plant cell walls. Agri. environ., 6, 295-337.

DEMEYER D. I., VERVAEKE I., 1984. Rumen digestion and microbial processes for increasing the feed value of poor quality materials. O.E.C.D. Workshop on Improved utilization of lignocellulosic materials with special reference to animal feed. Braunschweig 19-21 sept. 1984.

DINSDALE D., JANE MORRIS E., BRACON J. S. D., 1978. Electron microscopy of the microbial population present and their modes of attack on various cellulosic substrates undergoing digestion in the sheep rumen. Appl. environ. Microbiol., 36, 160-168.

DINSDALE D., CHENG K. J., WALLACE R. J., GOODLAD R. A., 1980. Digestion of epithelial tissues of the rumen wall by adherent bacteria in infused and conventionally fed sheep. Appl. environ. Microbiol., 39, 1059-1066.

DOUGHERTY R. W., 1965. Physiology of digestion in the ruminant. Butterworth, Washington.

DURAND M., 1984. Le rôle du soufre dans le rumen. Conséquences pour les besoins et recommandations d'apport chez le ruminant. In Le point sur le magnésium et le soufre en alimentation animale. Cycle appronfondi d'Alimentation animale, 14 juin 1984, I.N.A. Paris-Grignon.

DURAND M., KAWASHIMA R., 1980. Influence of minerals in rumen microbial digestion 375-408. In RUCKEBUSCH Y., THIVEND P., Digestive physiology and metabolism in ruminant. MTP Press Ltd, Lancaster.

DURAND M., BEAUMATIN Ph., DUMAY C., 1983. Estimation in vitro à l'aide de phosphore radioactif des besoins en phosphore des microorganisme du rumen. Reprod. Nutr. Dévelop., 23, 727 739 .

EADIE J. M., 1962. The development of rumen microbial populations in lambs and calves under various conditions of management. J. Microbiol., 29, 563-578.

FAY J. P., CHENG K. J., COSTERTON J. W., 1979. Production of alkaline phosphatase by epithelial cells and adherent bacteria of the bovine rumen and abomasum. Can. J. Microbiol., 25, 932936.

FONTY G., JOUANY J. P., SENAUD J., GOUET Ph., GRAIN J., 1984. The evolution of microflora, microfauna and digestion in the rumen of lambs from birth to 4 months. Can. J. anim. Sci., 64. (suppl.), 165-166.

FORSBERG C. W., LAM K., 1977. Use of adenosine triphosphate as an indicator of the microbial biomass in rumen contents. Appl. environ. Microbiol., 33, 528-537.

FREELAND W. J., JANZEN D. H., 1974. Cité par VAN SOEST, 1982. Nutritional ecology of the ruminant. p. 92, $\mathrm{O}$ and B. Books, Corvallis, Oregon.

GRAIN J., 1967. Le métabolisme des ciliés du rumen. Ann. Biol., VI, 17-45.

GRAIN J., SENAUD J., 1984. New data on the degradation of fresh lucerne fragments by the rumen ciliate Epidinium Ecaudatum : attachment, ingestion and digestion. Can J. anim. Sci,, 64 (Suppl.), 26.

HARRISON D. G., MC ALLAN A. B., 1980. Factors affecting microbial growth yields in the reticulo rumen, 205-206. In Y. RUCKEBUSCH, P. THIVEND, Digestive and metabolism in ruminants. MTP Press Ltd, Lancaster.

HESPELL E. B., BRYANT M. P., 1979. Efficiency of rumen microbial growth :influence of some theorical and experimental factors on Y (ATP). J. anim. Sci., 49, 1640-1659.

HESPELL R. B., 1981. Ruminal microoganisms - Their significance and nutritional value. Developments in industrial microbiology, 22 261-275.

HESPELL R. B., 1983. Influence of ammonia assimilation pathways and survival strategy on ruminal microbial growth. In GILCHRIST F. M. C., MACKIE R. I., Herbivore nutrition in the subtropics and tropics. The Sci. Press Ltd., Craighall 2024, South Africa.

HUNGATE R. E., 1942. Cité par HUNGATE (1966). The rumen and its microbes. Acad. Press, NewYork and London.

HUNGATE R. E., 1966. The rumen and its microbes. Acad. Press, New-York and London.

HUNGATE R. E., 1979. Evolution of a microbial ecologist. Ann. Rev. Microb., 33, 1-20.

IMAI S., OGIMOTO K., 1978. Scanning electron and fluorescent microscopic studies on the attachment of spherical bacteria to ciliate protozoa in the ovine rumen. Jap. J. vet. Sci., 40, 9-19.

IVERSON W. G., MILLIS N. F., 1977. Sucession of Streptococcus bovis strains with differing bacteriophage sensitivities in the rumen of two fistulated sheep. Appl, environ. Microbiol., 33, 810813. 
JACQUOT R., LE BARS H., SIMONNET H., 1958. Nutrition animal. Vol. I : Données générales sur la nutrition et l'alimentation. J.B. Baillere et Fils Ed. Paris.

JARRIGE R., 1960. The membrane constituents of herbage. Proc. 8th Int. Grassl. Gongr., 628-635.

JARRIGE R., 1978. Digestion. In Alimentation des ruminants. Ed. INRA Publ. Route de Saint-Cyr, 78000 Versailles, 23-45.

JARRIGE R., 1980 a. Place of herbivores in the agricultural ecosystems, 763-823.In Y. RUCKEBUSCH, P. THIVEND, Digestive physiology and metabolism in ruminants. MTP. Press, Lancaster.

JARRIGE R., 1980 b. Chemical methods for predicting the energy and protein value of forages. Ann. Zootech., 29, $\mathrm{n}^{\circ}$ H.S., 299-323.

JOBLIN K. N., 1981. Isolation, enumeration and maintenance of rumen anaerobic fungi in roll tubes. Appl. environ. Microbiol., 42, 1119-1122.

JOUANY J. P., 1978. Contribution à l'étude des protozoaires ciliés du rumen : leur dynamisme, leur róle dans la digestion et leur intérêt pour le ruminant. Th. d'Etat, Univ. Clermont II.

KRUMHOLZ L. R., FORSBERG C. W., VEIRA D. M., 1983. Association of methanogenic bacteria with rumen protozoa. Can. J. Microbiol., 29, 676.

LATHAM M. J., 1980. Adhesion of rumen bacteria to plant cell wall, 339-350. In R. C. W. BERKELEY, J. M. LYNCH, J. MELLING, P.R. RUTTER, B. VINCENT, Microbial adhesion to surfaces. Ellio Howood Ltd, Chichester.

LUND A., 1974. Yeasts and moulds in the bovine rumen. J. gen. Microbiol., 81, 453-462.

MATTEUZI D., SOZZI T., 1971. Bifidobacterium bacteriophage from calf rumen. $Z$. Allg. Mikrobiol., 11, 57-58.

Mc COWAN R. P., CHENG K. J., BAILEY C. B. M., COSTERTON J. W., 1978. Adhesion of bacteria to epithelial cell surfaces within the reticulo-rumen of cattle. Appl. environ. Microbiol., 35. $149-55$.

Mc COWAN R. P., CHENG K. J., COSTERTON J. W., 1980. Adherent bacterial population on the bovine rumen wall : Distribution patterns of adherent bacteria. Appl. environ. Microbiol., 39. 233-241.

Mc DONALD I. W., WARNER A. C. I., 1975. Digestion and metabolism in the ruminant. The Univ. New-England Publ. Unit, Armidale.

MEAD L. J., JONES G. A., 1981. Isolation and presomptive identification of adherent epithelial bacteria (Epimural bacteria) from the ovine rumen wall. Appl. environ. Microbiol., 41, 1020-1028.

MERRY R. J. Mc ALLAN A. B., 1983. A comparison of chemical composition of mixed bacteria harvested from the liquid and solid fractions of rumen digesta. Brit. J. Nutr., 5, 701-709.

MINATO H., ENDO A., HIGUCHI M., OOTOMO Y., VERMURA T., 1966. Ecological treatise on the rumen fermentation. I. The fractionation of bacteria attached to the rumen digesta solids. $J$. gen. Microbiol., 12, 39-52.

MINATO H., SUTO T., 1979. Technique for fractionation of bacteria in rumen microbial ecosystem. I. Attachment of rumen bacteria to starch granules and elution of bacteria attacted to them. $J$. gen. Appl. Microbiol., 22, 259-276.

MINATO H., SUTO T., 1981. Technique for fractionation of bacteria in rumen microbial ecosystem. IV. Attachment of rumen bacteria to cellulose powder and elution of bacteria attached to it. J. gen. appl. Microbiol., 27, 21-31.

OGIMOTO K., IMAI S., 1981. Atlas of rumen microbiology. Jap. Sci. Soc. Press, Tokyo.

ORPIN G. C., 1977. On the induction of zoosporigenesis in the rumen phycomycetes Neocallimastix frontalis, Piromonas communis, Sphaeromonas communis. J. gen Microbiol., 101, 181-189.

ORPIN G. C., 1984. The role of ciliate protozoa and fungi in the rumen digestion of plant cell walls. Anim. Feed Sci. Technol., 10, 121-143.

ORPIN G. C., HALL F. J. H., 1977. Attachment of the rumen holotrich protozoon /sotricha intestinalis to grass particles. Proc. Soc. gen. Microbiol., 14, 82-83.

ORPIN G. C., LETCHER A. J., 1978. Some factors controlling the attachment of the rumen holotrich protozoa /sotricha intestinalis and I. prostoma to plant particules in vitro. J. gen. Microbiol., 106, 33-40.

ORPIN G. C., MUNN E. A., 1974. The occurence of bacteriophages in the rumen and their influence on rumen bacterial populations. Experientia, 30, 1018-1020.

PHILLIPSON A. T., 1970. Physiology of digestion and metabolism in the ruminant. Oriel Press, Newcastle upon Tyne. 
RITCHIE A. E., ROBINSON I. M., ALLISON M. J., 1970. Rumen bacteriophage : survey of morphological types. 7e Congr. int. Microscop. Electron. Grenoble, 333-334.

ROBINSON I. M., ALLISON M.J., HARTMAN P.A., 1975. Anaeroplasma abactoclasticum gen. Nov. sp. nov. : an obligatery anaerobic mycoplasma from the rumen. Int. J. Syst. Bacteriol., 25, 173-181.

RUCKEBUSCH Y., KAY R. N. B., 1971. Etude critique de la motricité gastrique chez les bovins. Ann. Rech. Vet., 2, 99-136.

RUCKEBUSCH Y., THIVEND P., 1980. Digestive physiology and metabolism in ruminant. MTP press Ltd, Lancaster, England.

RUSSEL J. B., HESPELL R. B., 1981. Microbial rumen fermentation. J. Dairy Sci., 64, 1133-1169.

SMITH R. H., 1979. Synthesis of microbial nitrogen compounds in the rumen and their subsequent digestion. J. anim. Sci., 49, 1604-1614.

VAN SOEST P., 1982. Nutritional ecology of the ruminant. $\mathrm{O}$ and B. Books, Corvallis, Oregon.

VERMOREL M., 1978. Energie. In Alimentation des Ruminants Ed. INRA Publ. Route de St-Cyr 78000 Versailles.

WALLACE R. J., CHENG K. J., DINSDALE D., ØRSKOV E. R., 1979. An independent microbial flora of the epithelium and its role in the ecomicrobiology of the rumen. Nature, 279, 424-426.

WILLIAMS A. G., 1982. The metabolism and significance of ciliate protozoa in the rumen ecosystem. Report Hannah Res. Inst., 93-110.

WOLIN M.J., 1975. Interactions between the bacterial species of the rumen, 134-148. In Mc DONALD I. W., WARNER A. C. I. Digestion and metabolism in the ruminant. Univ. New England Publ. Unit, Armidale. 